\title{
Behavior of people: Role of extraversion and loneliness
}

\author{
Soma Parija*, Asmita Shukla \\ School of Humanities, Social Sciences and Management, Indian Institute of Technology Bhubaneswar, India \\ Email address: \\ Somaparija85@gmail.com (S. Parija), asmitas@gmail.com (A. Shukla)
}

\section{To cite this article:}

Soma Parija, Asmita Shukla. Behavior of People: Role of Extraversion and Loneliness. Psychology and Behavioral Sciences. Vol. 3, No. 1, 2014, pp. 17-24. doi: 10.11648/j.pbs.20140301.14

\begin{abstract}
This empirical study demonstrates that extraversion and loneliness as important variables predicting depression, subjective happiness, satisfaction with life and online flow experience. Extraversion was categorized into two categories, namely high and low extraversion. Similarly loneliness was also categorized into high and low loneliness. Data was collected from 342 participants (184 males and 158 females) using a structured questionnaire that contained all the variables of the study. Statistical techniques such as reliability and multivariate analysis of variance (MANOVA) were used to analyze the data. Results revealed significant main effects of extraversion and loneliness on depression, subjective happiness, satisfaction with life and online flow experience. High extraversion and low loneliness had a negative effect on depression and online flow experience, and a positive effect on subjective happiness and satisfaction with life. Interaction effects indicated that an individual has low depression and low online flow experience, and high subjective happiness and high satisfaction with life when he/she is extroverted in nature and suffers from low degree of loneliness. The details of findings of the study have been suitably discussed.
\end{abstract}

Keywords: Personality, Extraversion, Loneliness

\section{Introduction}

Personality is an individual's unique and relatively stable patterns of behavior, thoughts and emotions [1]. Research has identified two main personality tendencies: extraversion and neuroticism [2]. The extrovert is a friendly person who seeks company, desires excitement, and takes risks. This personality variable influences the behavior of individuals in the real and the virtual world.

A relationship exists between extraversion and depression. Depression is a mood disorder in which individuals experience extreme unhappiness, lack of energy, and several related symptoms (DSM - IV). Reference [3] examined sixty Iranian patients to probe the relationship between big five personality variables and depression. They used linear regression analysis and found out that depression levels were negatively predicted by extraversion. In another study, the personality variables, extraversion and neuroticism predicted depressive and anxiety symptoms [4]. Reference [5] used Pearson correlation analysis to find out the correlation between personality and depression of medical students. Results showed significant negative correlation between extraversion and depression. Reference [6] evaluated the relationship between NEO Five-Factor Inventory, and depressive and anxiety disorders. Structural equation modelling was used and it was found out that extraversion was inversely related to major depressive disorder. A study by, as in [7] revealed that extraversion and depression were negatively correlated as the patients with major depressive disorder had negative z-score of extraversion. College students in Taiwan were assessed for their personality traits and depressive states and it was found out that low extraversion, agreeableness and conscientiousness, and high neuroticism predicted depression in them [8]. A study was made to see the relationship between depression and extraversion [9]. It was conducted on male twins and found out that extraversion was negatively correlated with depression. Reference [10] analyzed the association between the personality factors and depression in children and adolescents. Depressive symptoms were associated with lower levels of extraversion.

Significant relationship exists between personality traits and subjective well-being of individuals. Subjective happiness is defined as a mental state of well-being characterized by positive emotions ranging from contentment to intense joy [11]. Reference [12] reported a positive relationship between extraversion and subjective happiness from a survey in South Korea. In another study, as 
in [13], it was also found out that higher the individual scored on extraversion, the grater was his self-reported happiness. Similarly, as in [14] had found similar results. Higher extraversion was associated with higher happiness in life. Reference [15] examined to what extent personality trait, extraversion was significantly correlated with happiness and also reported a positive correlation between extraversion and subjective happiness. Reference [16] used Eysenck Personality Questionnaire and Oxford Happiness Inventory as measures. They used regression analysis and found a positive relationship between extraversion and happiness. A correlation also exists between Oxford Happiness Inventory and NEO Five Factor Inventory indicating a positive correlation between extraversion and happiness [17]. A study examined self-rated happiness with personality traits [18]. Extraversion was a direct predictor of subjective happiness as revealed by the regression analysis scores. The relationship between personality and happiness was examined by [19]. 150 adults completed the Eysenck Personality Questionnaire and Oxford Happiness Scale. A significant positive direct relationship was obtained through regression analysis of extraversion with happiness.

Satisfaction with life is an overall assessment of feelings and attitudes about one's life at a particular point in time ranging from negative to positive [20]. It is also influenced by extraversion. Personality is a significant predictor of satisfaction with life. Extraversion predicted life satisfaction [21]. Reference [22] tested the relationship between personality traits and satisfaction with life. Regression analysis was used to analyze the data and it was found out that extraversion and neuroticism were the best predictors of satisfaction with life. Higher extraversion scores were associated with higher satisfaction with life [23]. Extraversion exerts a positive effect on the long-term satisfaction with life of Dutch people [24]. Reference [25] reported a positive relationship between extraversion and satisfaction with life from a survey in South Korea.

An individual's action in the flow state is experienced as "the holistic sensation that people feel when they act with total involvement [26]". Online flow was defined "as the state occurring during network navigation which is: 1) characterised by a seamless sequence of responses facilitated by machine interactivity, 2) intrinsically enjoyable, 3) accompanied by a loss of self-consciousness, and 4) self-reinforcing [27]". It has been reported that the introverted people locate their "real me" on the internet, while extroverts locate their "real me" through traditional social interaction [28]. Reference [29] examined whether extraversion, openness, conscientiousness, skill and online flow were related or not. It was found out that extraversion negatively influenced online flow and, openness and conscientiousness positively influenced online flow experience of individuals.

It has been examined that loneliness also influences the life of individuals in cyberspace and in the real world. Loneliness is "the unpleasant experience that occurs when a person's network of social relationships is deficient in some important way, either quantitatively or qualitatively [30]”. Reference
[31] examined the elderly population and assessed their level of loneliness and depression. The results showed a positive correlation between loneliness and depression in the elderly population. A significant positive relationship between depression and loneliness was found in students of South Africa [32]. In a study, as in [33] it was reported that loneliness predicted depressive symptoms. Reference [34] had also found out that loneliness predicted depression. Regression analysis demonstrated that depression was predicted by loneliness scores. Reference [35] examined the prevalence of loneliness and depression among different age groups in the United Kingdom. Results reported an association of depression and loneliness for all age groups.

The variable, loneliness has an influence on subjective happiness. A negative relationship was found between loneliness and subjective happiness in adolescence [36]. Reference [37] examined the older population and demonstrated that loneliness was negatively correlated with happiness. Reference [38] also reported a negative correlation between loneliness and happiness.

Loneliness was associated with low satisfaction with life [39]. Adolescents who felt lonely were dissatisfied with their lives [40]. Reference [41] assessed life satisfaction and loneliness in Turkish university students and reported that satisfaction with life negatively predicted loneliness. Reference [42] demonstrated that people who lived alone had lower satisfaction with their relationship with others and a lower need to belong than those who lived with others. Studies also report that social and emotional loneliness correlates with life satisfaction [43]. Reference [44] demonstrated that social and emotional loneliness were negative predictors of satisfaction of life. Reference [45] assessed loneliness and satisfaction with life in middle-aged Spanish women. Regression analysis reported that higher loneliness correlated with lower life satisfaction. Reference [46] investigated nursing students in Usak University and reported that loneliness predicted satisfaction with life.

Reference [47] concept of the "flow experience" also describes a significant coping mechanism for people undergoing solitary ordeals. Individuals who experience flow have problem in coping with adversity and tend to be stressed rather than challenged by life's difficulties. Reference [48] reported that loneliness was positively correlated with the time spent online in chat rooms. Reference [49] also assessed the association between loneliness and the duration of internet usage. Results showed that loneliness was positively correlated with Internet usage. Lonely people used the Internet more frequently than the non-lonely individuals [50]. Another study also reported positive association between loneliness and internet use [51]. Lonely individuals found their relationship with their online partners to be of great importance [52]. But the relationship between loneliness and online flow experience has not been studied yet.

In the light of the existing research, it can be stated that extraversion and loneliness have effects on depression, subjective happiness, satisfaction with life and online flow 
experience, though relatively little is known about how interactions of the personality variable (extraversion) and loneliness influence depression, subjective happiness, satisfaction with life and online flow experience.

\section{Objectives}

The specific research objectives of this study are as follows:

1. To examine whether extraversion determine depression, subjective happiness, satisfaction with life and online flow experience.

2. To examine whether loneliness determine depression, subjective happiness, satisfaction with life and online flow experience.

3. To examine whether locus of control and loneliness interact with each other to effect depression, subjective happiness, satisfaction with life and online flow experience.

\section{Hypotheses}

The following hypotheses are proposed for the present research:

H1a: The higher the individual is on extraversion, the lower would be his/her depression.

H1b: The higher the individual is on extraversion, the higher would be his/her subjective happiness.

H1c: The higher the individual is on extraversion, the higher would be his/her satisfaction with life.

H1d: The higher the individual is on extraversion, the lower would be his/her online flow experience.

$\mathrm{H} 2 \mathrm{a}$ : The higher the individual is on loneliness, the higher would be his/her depression.

$\mathrm{H} 2 \mathrm{~b}$ : The higher the individual is on loneliness, the lower would be his/her subjective happiness.

$\mathrm{H} 2 \mathrm{c}$ : The higher the individual is on loneliness, the lower would be his/her satisfaction with life.

$\mathrm{H} 2 \mathrm{~d}$ : The higher the individual is on loneliness, the higher would be his/her online flow experience.

$\mathrm{H} 3 \mathrm{a}$ : The higher the individual is on extraversion and lower is on loneliness, the lower would be his/her depression.

$\mathrm{H} 3 \mathrm{~b}$ : The higher the individual is on extraversion and lower is on loneliness, the higher would be his/her subjective happiness.

$\mathrm{H} 3 \mathrm{c}$ : The higher the individual is on extraversion and lower is on loneliness, the higher would be his/her satisfaction with life.

H3d: The higher the individual is on extraversion and lower is on loneliness, the lower would be his/her online flow experience.

\section{Proposed Conceptual Framework}

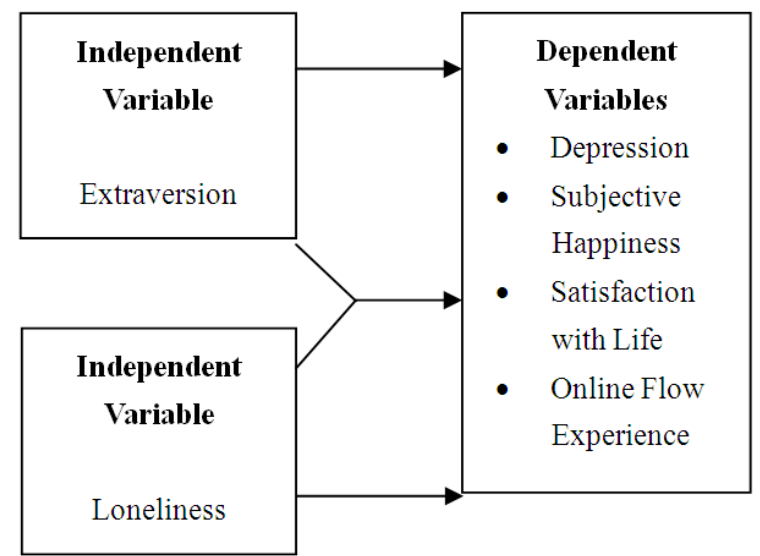

Figure 1. Analysis Framework for Interaction between Extraversion and Loneliness

\section{Methodology}

The methodology used for carrying out the research work includes the research design, the participants, the measures and procedure used for data collection.

\subsection{Research Design}

A 2(extraversion) $\mathrm{X}$ 2(loneliness) between subjects factorial design employing 4 treatment combination was used where there were two categories of extraversion (High: $\mathrm{H}$ - extraversion and Low: L - introversion) and two categories of loneliness (High: $\mathrm{H}$ and Low: L).

\subsection{Participants}

Three hundred and forty two valid questionnaires were obtained from the survey in India. It included one hundred and eighty four males and one hundred and fifty eight females. Age range of one hundred and twenty six participants were of 18-24 age range, one hundred and nine were of 25-34 years of age, fifty eight participants were 35-44 years of age, thirty were of 45-54 years of age and nineteen participants were 55-64 years of age. The sample comprised one hundred and thirteen students, fifty eight software professionals, thirty four academicians, forty nine bankers, forty five corporate executives, twenty five housewives and eighteen were from other occupations.

\subsection{Measures}

The items used to measure the variables were taken from existing standardized scales as per the need of the study. A description of the measures used in the present study is given below.

\subsubsection{Extraversion}

The twelve-item scale of extraversion was adapted from Eysenck Personality Questionnaire Revised (EPQ-R) developed by Eysenck and Eysenck (1985). It assesses the personality traits of a person. The responses were measured 
on a scale of Yes (1) and No (0). A high score indicates extraversion while a low score indicates introversion.

\subsubsection{Loneliness}

The six-item scale of loneliness was adapted from Gierveld and Tilburg (2006). This scale measures the overall loneliness of an individual. The items were measured on a 6-point Likert Scale ranging from 'very strongly disagree' (1) to 'very strongly agree' (6). A high score indicates higher loneliness and a low score indicates lower loneliness.

\subsubsection{Depression}

The twenty-item scale of depression was adapted from Zung Self-Rating Depression Scale, designed by Zung (1965) to assess the level of depression for individuals. There are ten positively worded and ten negatively worded questions. The items were measured on a 6-point Likert Scale ranging from 'never' (1) to 'always' (6). A higher score indicates higher level of depression and a lower score indicates a lower level of depression.

\subsubsection{Subjective Happiness}

The four-item scale of subjective happiness was adapted from Subjective Happiness Scale (SHS), developed by Lyubomirsky (1997). The items were measured on a 6-point Likert Scale. A higher score indicates higher subjective happiness and a lower score indicates lower subjective happiness.

\subsubsection{Satisfaction with Life}

The five-item scale of satisfaction with life was adapted from Satisfaction with Life Scale (SWLS), developed by Diener, Emmons, Larsen and Griffin (1985). SWLS is a global measure of life satisfaction. The items were measured on a 6-point Likert Scale ranging from 'very strongly disagree' (1) to 'very strongly agree' (6). A high score indicates higher life satisfaction and a low score indicates lower life satisfaction.

Table 1. Cronbach's Alpha Reliability of the Measures of the Study

\begin{tabular}{lcc}
\hline & Reliability & Number of items \\
\hline Independent Variables & .96 & 12 \\
Extraversion & .98 & 6 \\
Loneliness & & \\
Dependent Variables & .99 & 20 \\
Depression & .95 & 4 \\
Subjective Happiness & .96 & 5 \\
Satisfaction with Life & .98 & 17 \\
Online Flow Experience & & \\
\hline
\end{tabular}

\subsubsection{Online Flow Experience}

The seventeen-item scale of online flow experience was adapted from Novak and Hoffman (2003). The items were measured on a 6-point Likert Scale. A high score indicates higher online flow experience and a low score indicates lower online flow experience.

Cronbach's alpha was computed to examine the reliability of the measures employed in the study. The cronbach's alpha reliability of the measures is given in Table 1. It showed that the coefficient of internal consistency (Cronbach's alpha) for the items of the measures for the sample of the study was found to be acceptable.

\subsection{Procedure}

Data was collected through both online and offline method of data collection using a questionnaire that comprises questions seeking information about demographics of the respondents namely name, gender, age, educational level, occupation, name of the company/organization/institution and email. Then it included questions on independent variables (extraversion and loneliness) and the dependent variables (depression, subjective happiness, satisfaction with life and online flow experience) of the study.

The participants of this study $(\mathrm{N}=342)$ were categorized into high and low on extraversion and loneliness on the basis of their mean scores. The mean scores are shown in Table 2 and the number of participants per category is shown in Table 3.

Table 2. Mean Scores

\begin{tabular}{cc}
\hline & Mean Score \\
\hline Extraversion & 5.26 \\
Loneliness & 23.92 \\
\hline
\end{tabular}

Table 3. Categorization of the Participants on the basis of Mean Score

\begin{tabular}{|c|c|c|c|}
\hline & \multicolumn{2}{|c|}{ Categories } & \multirow{2}{*}{ Total } \\
\hline & High & Low & \\
\hline Extraversion & 141 & 201 & 342 \\
\hline Loneliness & 221 & 121 & 342 \\
\hline
\end{tabular}

\section{Results and Interpretation}

Multivariate analysis of variance (MANOVA) was computed to explore the main and interaction effects of extraversion and loneliness on depression, subjective happiness, satisfaction with life and online flow experience. Analysis was carried out using SPSS v.18.

Table 4. Summary of Results of MANOVA of Extraversion on Depression, Subjective Happiness, Satisfaction with Life and Online Flow Experience

\begin{tabular}{lcccc}
\hline Variables & df & MS & F & пp2 \\
\hline Extraversion & & & & \\
DEP & 1 & 32.70 & $77.05^{*}$ & .19 \\
SH & 1 & 138.82 & $176.55^{*}$ & .34 \\
SWL & 1 & 43.52 & $56.79^{*}$ & .14 \\
OFE & 1 & 114.69 & $163.80^{*}$ & .33 \\
\hline
\end{tabular}

$\mathrm{N}=342, * \mathrm{p}<.05, \mathrm{DEP}=$ Depression, $\mathrm{SH}=$ Subjective Happiness and SWL $=$ Satisfaction with Life, OFE $=$ Online Flow Experience

\subsection{Main Effects}

Hypotheses 1 deal with the main effects of extraversion on individual's depression, subjective happiness, 
satisfaction with life and online flow experience. H1 stated that higher the individual is on extraversion, the lower would be his/her depression (H1a) and online flow experience (H1d); and higher would be his/her subjective happiness (H1b) and satisfaction with life (H1c).

The results indicated significant main effects of extraversion on depression, subjective happiness, satisfaction with life and online flow experience (Table 4), thus H1 (a-d) were accepted.

Hypotheses 2 deal with the main effects of loneliness on individual's depression, subjective happiness, satisfaction with life and online flow experience. H2 stated that higher the individual is on loneliness, the higher would be his/her depression ( $\mathrm{H} 2 \mathrm{a})$ and online flow experience $(\mathrm{H} 2 \mathrm{~d})$; and lower would be his/her subjective happiness (H2b) and satisfaction with life (H2c).

The results indicated significant main effects of loneliness on depression, subjective happiness, satisfaction with life and online flow experience (Table 5), thus H2 (a-d) were accepted.

Table 5. Summary of Results of MANOVA of Loneliness on Depression, Subjective Happiness, Satisfaction with Life and Online Flow Experience,

\begin{tabular}{lcccc}
\hline Variables & df & MS & F & १р2 \\
\hline Loneliness & & & & \\
DEP & 1 & 327.30 & $771.32^{*}$ & .70 \\
SH & 1 & 107.11 & $136.21^{*}$ & .29 \\
SWL & 1 & 208.46 & $272.00^{*}$ & .45 \\
OFE & 1 & 154.55 & $220.72^{*}$ & .40 \\
\hline
\end{tabular}

$\mathrm{N}=342, * \mathrm{p}<.05, \mathrm{DEP}=$ Depression, $\mathrm{SH}=$ Subjective Happiness and SWL $=$ Satisfaction with Life, OFE $=$ Online Flow Experience

Table 6. Summary of Results of MANOVA of the Interaction Effects of Extraversion and Loneliness on Depression, Subjective Happiness, Satisfaction with Life and Online Flow Experience

\begin{tabular}{|c|c|c|c|c|}
\hline Variables & df & MS & $\mathbf{F}$ & $\eta p 2$ \\
\hline \multicolumn{5}{|c|}{ Locus of Control * Loneliness } \\
\hline DEP & 1 & 24.73 & $58.27 *$ & .15 \\
\hline $\mathrm{SH}$ & 1 & 8.43 & $10.72 *$ & .03 \\
\hline SWL & 1 & 4.37 & $5.70 *$ & .02 \\
\hline OFE & 1 & 40.62 & $58.02 *$ & .15 \\
\hline \multicolumn{5}{|l|}{ Error } \\
\hline DEP & 338 & .42 & & \\
\hline SH & 338 & .79 & & \\
\hline SWL & 338 & .77 & & \\
\hline OFE & 338 & .70 & & \\
\hline
\end{tabular}

$\mathrm{N}=342, * \mathrm{p}<.05, \mathrm{DEP}=$ Depression, $\mathrm{SH}=$ Subjective Happiness and $\mathrm{SWL}$ $=$ Satisfaction with Life, OFE $=$ Online Flow Experience

\subsection{Interaction Effects}

$\mathrm{H} 3 \mathrm{a}, \mathrm{H} 3 \mathrm{~b}, \mathrm{H} 3 \mathrm{c}$ and $\mathrm{H} 3 \mathrm{~d}$ deal with the interaction effects of extraversion and loneliness on depression, subjective happiness, satisfaction with life and online flow experience. It was hypothesized that the higher the individual is on extraversion and lower is on loneliness, the lower would be his/her depression (H3a) and online flow experience (H3d); and lower would be his/her subjective happiness (H3b) and satisfaction with life $(\mathrm{H} 3 \mathrm{c})$.

The interaction effects of extraversion and loneliness are shown in Table 6 . The results revealed significant interaction effects of extraversion and loneliness on depression, subjective happiness, satisfaction with life and online flow experience which supported the hypotheses H3 (a-d).

The results also revealed that if an individual is high on extraversion and low on loneliness, , the means of depression and online flow experience were lowest, and the means of subjective happiness and satisfaction with life were highest than any other categories of extraversion and loneliness. The means for the categories of extraversion and loneliness on depression, subjective happiness, satisfaction with life and online flow experience are given in Table 7 to 10. Therefore, hypotheses H3a, H3b, H3c and H4d were supported.

Table 7. Means of Categories of Extraversion and Loneliness on Depression

\begin{tabular}{lll}
\hline Mean Scores for Categories & \\
\hline & Loneliness (High) & Loneliness (Low) \\
Extraversion (High) & 3.02 & 1.42 \\
Extraversion (Low) & 4.33 & 1.51 \\
\hline
\end{tabular}

Table 8. Means of Categories of Extraversion and Loneliness on Subjective Happiness

\begin{tabular}{lll}
\hline \multicolumn{2}{l}{ Mean Scores for Categories } \\
\hline & Loneliness (High) & Loneliness (Low) \\
Extraversion (High) & 4.50 & 5.41 \\
Extraversion (Low) & 2.71 & 4.33 \\
\hline
\end{tabular}

Table 9. Means of Categories of Extraversion and Loneliness on Satisfaction with Life

\begin{tabular}{lll}
\hline \multicolumn{2}{l}{ Mean Scores for Categories } \\
\hline & Loneliness (High) & Loneliness (Low) \\
Extraversion (High) & 3.54 & 5.05 \\
Extraversion (Low) & 2.48 & 4.50 \\
\hline
\end{tabular}

Table 10. Means of Categories of Extraversion and Loneliness on Online Flow Experience

\begin{tabular}{lll}
\hline \multicolumn{2}{l}{ Mean Scores for Categories } & \\
\hline & Loneliness (High) & Loneliness (Low) \\
Extraversion (High) & 2.61 & 1.87 \\
Extraversion (Low) & 4.69 & 2.40 \\
\hline
\end{tabular}

These means are presented graphically in figures 2-5. These graphical presentations also support the Hypotheses H3 (a-d). 


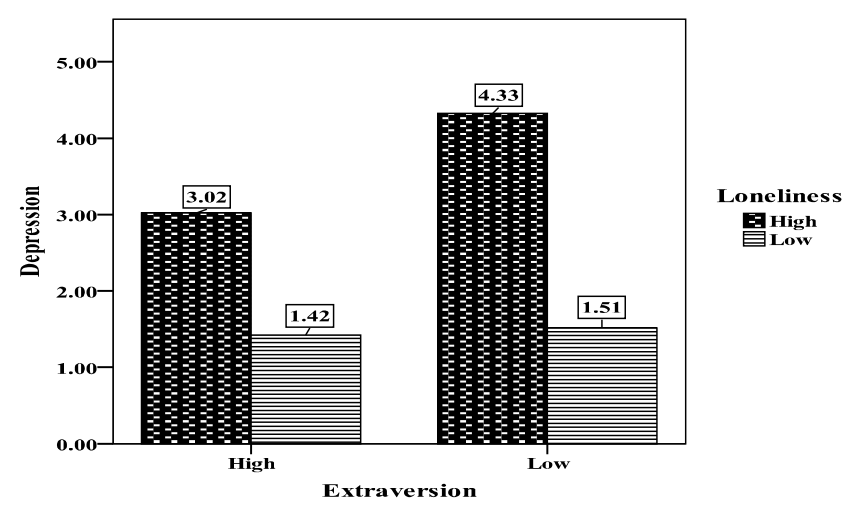

Figure 2. Means of Categories of Extraversion and Loneliness on Depression

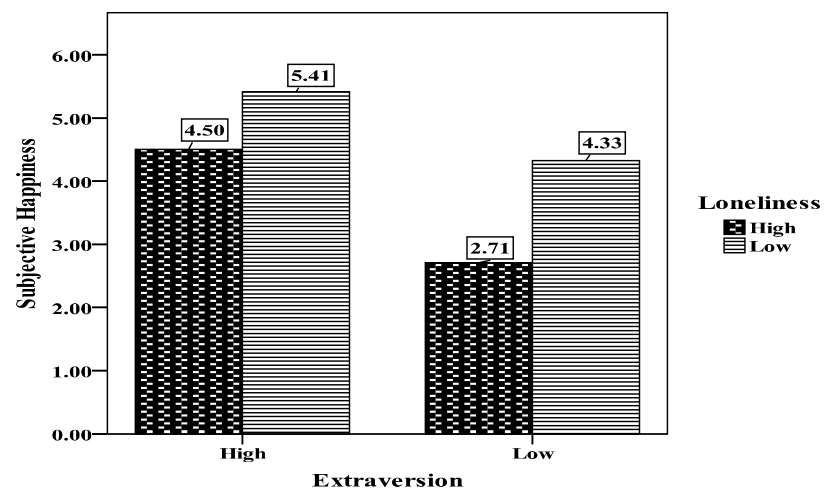

Figure 3. Means of Categories of Extraversion and Loneliness on Subjective Happiness

\section{Discussion and Conclusion}

The present study is an intense attempt to explore empirically the integrative role of personality variable, extraversion and loneliness in determining the online behavior of individuals as well as their level of depression, subjective happiness and satisfaction with life.

Results of MANOVA indicated that extraversion had a negative effect on depression and online flow experience, and a positive effect on subjective happiness and satisfaction with life. These results are also consistent with earlier findings. Extroversion often includes a higher frequency of social interaction which in turn satisfies the individual's need for social approval, thereby enhancing an extroverted person's subjective happiness and satisfaction with life. At the same time, a higher frequency of social interaction also reduces depression rates among extroverted people. This reduces their need for supplementing their social life with virtual social interactions, thus leading to low online flow experience.

The results of the present research also revealed that loneliness had a positive effect on depression and online flow experience. And it was found to have a negative effect on subjective happiness and satisfaction with life. The results are consistent with earlier findings. Individuals who characterize themselves as lonely or tend to spend most of their time alone would be prone to higher rates of depression as their seclusion from the extraneous social factors leads to inhibitions about

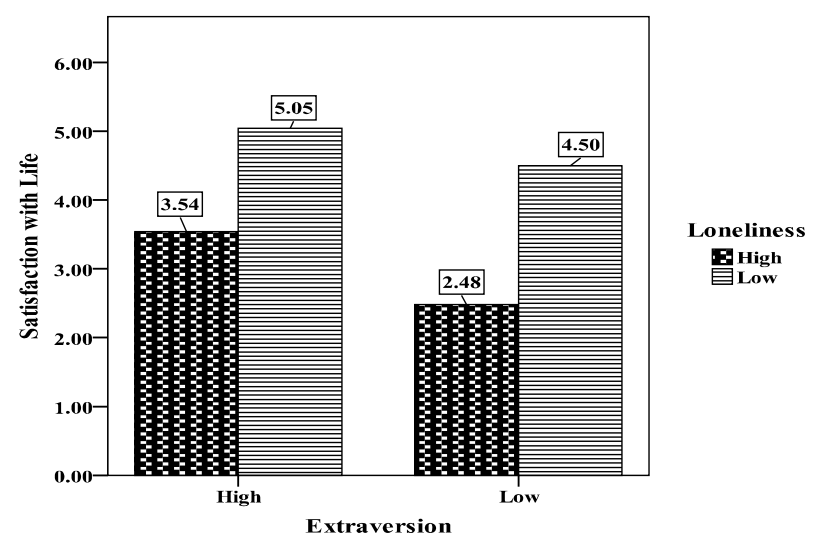

Figure 4. Means of Categories of Extraversion and Loneliness on Satisfaction with Life

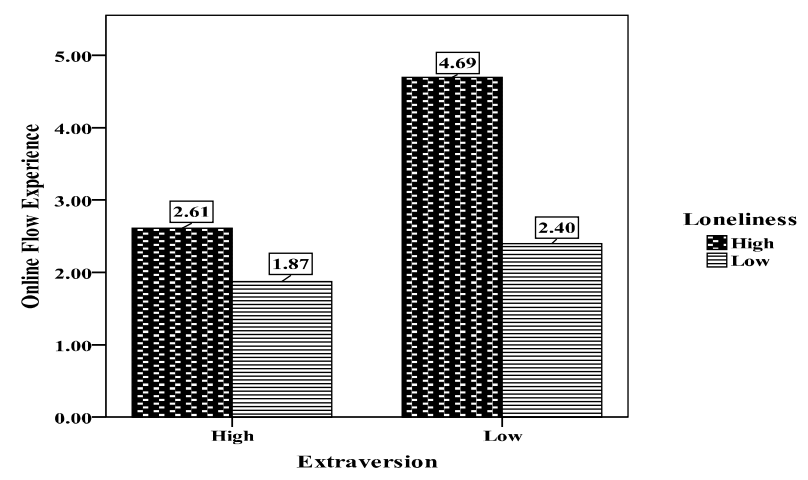

Figure 5. Means of Categories of Extraversion and Loneliness on Online Flow Experience

oneself, which causes a person to be occupied with one's own self to the extent that it prohibits them from successfully socializing with other people. This form of social and psychological isolation coupled with the constant preoccupation with oneself, makes lonely people more prone to dwell on their personal flaws and lacunae which would eventually lead to higher rates of depression amongst lonely people. Man being a gregarious animal by nature, isolation from extraneous social elements which is a characteristic of loneliness, also invariably leads to a lower subjective happiness and satisfaction with life resulting from the lack of social interaction with other human beings which a lonely person subjects him or herself to. The virtual social interactions and experience of these lonely people serves as a form of redemption for all the lack of social interactions and the seclusion of their real lives from extraneous social variables. The internet simulates social interaction through social media, instant messaging and other such features, which allow such individuals to have a constructed sense of socializing with other people without physical proximity or exposure. Therefore, they have higher online flow experience.

The interactive role of extraversion and loneliness was also evident in the results which imply that when the extroverted nature of a person will increase and his/her loneliness will gradually decrease, then his/her level of depression will reduce further and subjective happiness and satisfaction with life will be enhanced. At the same time the individual's online flow experience will also be reduced as 
these individuals do not engage themselves more in the virtual world. Thus it can be said that the higher the individual is on extraversion and lower is on loneliness, the lower would be his/her depression and online flow experience and higher would be his/her subjective happiness and satisfaction with life. The estimated marginal means (M) show that individuals who are high on extraversion $(\mathrm{H})$ and lower on loneliness (L) has lower depression, higher subjective happiness, higher satisfaction with life and lower online flow experience (6-point scale, Depression $\mathrm{M}=1.42$, Subjective Happiness $M=5.41$, Satisfaction with Life $M=$ 5.05, Online Flow Experience $M=1.87$ ). It is observed that extroverted people with a low degree of loneliness have lower rates of depression and low online flow experience. The higher frequency of social interaction characteristic to extroversion reduces feelings of loneliness among extroverted people, which in turn reduces the depression and the need for online flow experience. The subjective happiness and life satisfaction of these people are always on the higher side because these people do not have pent up emotions as they express themselves socially.

Finally, we can conclude that the individuals who are extroverted in nature fell less need for an aggressive online flow experience. Their need for acceptance was not only fulfilled outside in the real world but also their self reliant nature did not really require a high degree of social acceptance. Given that these individuals are less lonely and depressed they are seldom found online to quench their thirst for happiness. Due to their extroverted nature they stayed in a perpetual state of happiness and their online flow experience was low as it was only to keep in touch with others and know what others are doing rather than to search for happiness and acceptance online. Thus their online flow experience was only need based and not necessity based and thus always on a lower side.

\section{References}

[1] H. S. Friedman, and M. W. Schustack, Personality: Classic theories and modern research, Allyn and Bacon: Boston, 1999.

[2] H. J. Eysenck, and S. B. Eysenck, Manual of the Eysenck Personality Inventory, University of London Press: London, 1964.

[3] K. Mohamadi Hasel, M. A. Besharat, A. Abdolhoseini, S. Alaei Nasab, and S. Niknam, "Relationships of personality factors to perceived stress, depression, and oral lichen planus severity," International Journal of Behavioral Medicine, vol. 20, pp. 286-292, June 2013.

[4] P. Spinhoven, K. Roelofs, J. G. Hovens, B. M. Elzinga, P. van Oppen, F. G. Zitman, and B. W. Penninx, "Personality, life events and the course of anxiety and depression ," European Journal of Personality, vol. 25, pp. 443-452, Nov. 2011.

[5] M. B. Mustafa, R. Nasir, and F. Yosooff, "Parental support, personality, self-efficacy and depression among medical students," Procedia-Soxial and Behavioral Sciences, vol. 7 , pp. 419-424, 2010.
[6] A. J. Rosellini, and T. A. Brown, "The NEO five-factor inventory: Latent structure and relationships with dimensions of anxiety and depressive disorders in a large clinical sample," Assessment, vol. 18, pp. 27-38, March 2011.

[7] P. Jylha, T. Melartin, and E. Isomtsa, "Relationships of neuroticism and extraversion with axis I and II comorbidity among patients with DSM-IV major depressive disorder," Journal of Affective Dsorders, vol. 114, pp. 110-121, April 2009.

[8] L. L. Chien, H. C. Ko, and J. Y. W. Wu, "The five-facor model of personality and depressive symptoms: One-year follow-up," Personality and Individual Differences, vol. 43, pp. 1013-1023, Oct. 2007.

[9] A. H. Fanous, M. C. Neale, S. H. Aggen, and K. S. Kendler, "A longitudinal study of personality and major depression in a population-based sample of male twins," Psychological Medicine, vol. 37, pp. 1163-1172, Aug. 2007.

[10] M. A. C. Ortiz, and M. V. Del Barrio Gandara, "Temperamental and personality variables in child and adolescent depressive symptomatology," Psicothema, vol. 19, pp. 43-48, Feb. 2007.

[11] E. Diener, E. Suh, R. E. Lucas, and H. L. Smith, "Subjective well-being:three decades of progress," Psychological Bulletin, vol. 125, pp. 276-302, 1999.

[12] S. E. Ha, and S. Kim, "Personality and Subjective Well-Being: Evidence from South Korea," Social Indicators Research, vol. 111, pp. 341-359, 2013.

[13] R. Chan, and S. Joseph, "Dimensions of personality, domains of aspiration, and subjective well-being," Personality and Individual Differences, vol. 28, pp. 347-354, Feb. 2000.

[14] L. Lu, "The relationship between subjective well-being and psychosocial variables in Taiwan", The Journal of social psychology, vol. 135, pp. 351-357, Jun. 1995.

[15] W. Pavot, E. Diener, and F. Fujita, "Extraversion and happiness," Extraversion and happiness," Personality And Individual Differences, vol. 11. pp. 1299-1306, 1990.

[16] A. Furnham, and C. R. Brewin, "Personality and happiness," Personality and Individual Differences, vol. 11, pp. 1093-1096, 1990.

[17] A. Furnham, and H. Cheng, "Personality and Happiness," Psychological Reports, vol. 80, pp. 761-762, 1997.

[18] A. Furnham, and H. Cheng, "Personality, peer relations, and self-confidence as predictors of happiness and loneliness," Journal of Adolescence, vol. 25, pp. 327-339, 2002.

[19] N. Pishva, M. Ghalehban, A. Moradi, and L. Hoseini, "Personality and Happiness," Procedia-Social and Behavioral Sciences, vol. 30, pp. 429-432, 2011.

[20] E. Diener, "Subjective Well-Being," Psychological Bulletin, vol. 95 , pp. 542-575, 1984.

[21] I. E. Onyishi, and O. E. Okongwu, "Personality and social support as predictors of life satisfaction of Nigerian prisons officers", Social Sciences (Pakistan), vol. 8, pp. 5-12, 2013.

[22] N. Baudin, A. Aluja, J. P. Rolland, and A. Blanch, "The role of personality in satisfaction with life and sport," Behavioral Psychology, vol. 19, pp. 333-345, 2011. 
[23] J. W. Zhang, and R. T. Howell, "Do time perspective predict unique variance in life satisfaction beyond personality traits?," Personality and Individual Differences, vol. 50, pp. 1261-1266, Jun. 2011.

[24] J. P. M. Soons, and A. C. Liefbroer, "Patterns of life satisfaction, personality and family transitions in young adulthood," Advances in Life Course Research, vol. 14, pp. 87-100, Sep. 2009.

[25] S. E. Ha, and S. Kim, "Personality and Subjective Well-Being: Evidence from South Korea," Social Indicators Research, vol. 111, pp. 341-359, 2013.

[26] M. Csikszentmihalyi, Beyond boredom and anxiety, Josey-Bass: San Francisco, 1977.

[27] D. L. Hoffman, and T. P. Novak, "Marketing in Hypermedia Computer-Mediated Environments: Conceptual Foundations," Journal of Marketing, vol. 60, pp. 50-68, 1996.

[28] D. Perlman, and L. A. Peplau, Loneliness research: survey of empirical findings, US Government Printing Office: Washington, DC, 1984.

[29] C. I. Teng, L. S. Huang, S. P. Jeng, Y. J. Chou, and H. H. Hu, "Who may be loyal? Personality, flow experience, and customer e-loyalty," International Journal of Electronic Customer Relationship Management, vol. 6, pp. 20-47, Apr. 2012.

[30] Y. Amichai-Hamburger, G. Wainapel, and S. Fox, "On the Internet No One Knows I'm an Introvert: Extroversion, Neuroticism, and Internet Interaction," Cyberpsychology and Behavior, vol. 5, pp. 125-128, 2002.

[31] R. Aylaz, U. Akturk, B. Erci, H. Ozturk, and H. Aslan, "Relationship between depression and loneliness in elderly and examination of influential factors," Archives of Gerontology and Geriatrics, vol. 55, pp. 548-554, Nov. 2012.

[32] L. C. H. Doman, and A. Le Roux, "The relationship between loneliness and psychological well-being among third-year students: A cross-cultural investigation," International Journal of Culture and Mental Health, vol. 5, pp. 153-168, Nov. 2012.

[33] J. T. Cacioppo, L. C. Hawkley, and R. A. Thisted, "Perceived social isolation makes me sad: 5-year cross-lagged analyses of loneliness and depressive symptomatology in the Chicago health, aging, and social relations study," Psychology and Aging, vol. 25, pp. 453-463, Jun. 2010.

[34] T. W. Baskin, B. E. Wampold, S. M. Quintana, and R. D. Enright, "Belongingness as a Protective Factor Against Loneliness and Potential Depression in a Multicultural Middle School," The Counseling Psychologist, vol. 38, pp. 626-651, July, 2010.

[35] C. R. Victor, and K. Yang, "The prevalence of loneliness among adults: a case study of the United Kingdom," The Journal of Psychology, vol. 146, pp. 85-104, Jan. 2012.

[36] D. W. Moore, and N. R. Schultz Jr., "Loneliness at adolescence: Correlates, attributions, and coping," Journal of Youth and Adolescence, vol. 12, pp. 95-100, Apr. 1983.

[37] M. M. Y. Tse, A. M. H. Wong, and V. T. C. Wan, "Happiness among community-dwelling older persons: Is it related to pain and loneliness?," Journal of Pain Management, vol. 5, pp. 163-175, 2012.

[38] J. F. Schumaker, J. D. Shea, M. M. Monfries, and G. Groth-Marnat, "Loneliness and Life Satisfaction in Japan and Australia," The Journal of Psychology, vol. 127, pp. 65-71, 2010.

[39] M. Durak, and E. Senol-Durak, "Psychometric qualities of the ucla loneliness scale-version 3 as applied in a turkish culture," Educational Gerontology, vol. 36, pp. 988-1007, 2010.

[40] A. R. Ronka, A. Taanila, M. Koiranen, V. Sunnari, and A. Rautio, "Associations of deliberate self-harm with loneliness, self-rated health and life satisfaction in adolescence: Northern Finland Birth Cohort 1986 study," International Journal of Circmpolar Health, vol. 72, Article number 21085, 2013.

[41] S. Ozben, "Social skills, life satisfaction, and loneliness in Turkish university students," Social Behavior and Personality, vol. 41, pp. 203-214, 2013.

[42] D. Mellor, M. Stokes, L. Firth, Y. Hayashi, and R. Cummins, "Need for belonging, relationship satisfaction, loneliness, and life satisfaction," Personality and Individual Differences, vol. 45, pp. 213-218, Aug. 2008.

[43] V. L. Zammuner, "Italians'social and emotional loneliness: The results of five studies," World Academy of Science, Engineering and Technology, vol. 40, pp. 482-494, Apr. 2009.

[44] A. Salimi, "Social-emotional loneliness and life satisfaction," Procedia-Social and Behavioral Sciences, vol. 29, pp. 292-295, 2011.

[45] A. M. Fernandez-Alonso, M. Trabalon-Pastor, C. Vara, P. Chedraui, and F. R. Perez-Lopez, "Life satisfaction, loneliness and related factors during female midlife," Maturitas, vol. 72, pp. 88-92, May 2012.

[46] M. N. Akhunlar, "An investigation about the relationship between life satisfaction and loneliness of nursing students in Usak University," Procedia- Social and Behavioral Sciences, vol. 5, pp. 2409-2415, 2010.

[47] M. Csikszentmihalyi, Beyond Boredom and Anxiety, Jossey-Bass, San Francisco, CA, 1975.

[48] R. Carden, and S. Rettew, "Internet chat room use, satisfaction with life, and loneliness," Psychological Reports, vol. 98, pp. 121-122, Feb. 2006

[49] I. Stepanikova, N. H. Nie and X. He, "Time on the Internet at home, loneliness, and life satisfaction: Evidence from panel time-diary data", Computers in Human Behavior, vol. 26, pp. 329-338, May 2010.

[50] A. J. Campbell, S. R. Cumming, and I. Hughes, "Internet use by the socially fearful: Addiction or therapy?," Cyberpsychology and Behavior, vol. 9, pp. 69-81, Feb. 2006.

[51] M. K. Matsuba, "Searching for self and relationship online," Cyberpsychology and Behavior, vol. 9, pp. 275-284, Jun. 2006.

[52] K. Subrahmanyam and G. Lin, "Adolescents on the net: Internet use and well-being," Adolescence, vol. 42, pp. 659-677, Dec. 2007. 